\title{
Employees' Turnover, Knowledge Management and Human Recourse Management: A Case of Nitaqat Program
}

\author{
Nawaf Alshanbri, Malik Khalfan, M. Ali Noor, Debopriya Dutta, Kevin Zhang, and Tayyab Maqsood
}

\begin{abstract}
Employee turnover as a term and its sources have been introduced and conducted in several studies in the past few decades. The lost knowledge as a result of this turnover on a large scale as a" country scale" is the topic that will be discussed and presented in this paper. Nitaqat as a localization program that have been forced by the Saudi ministry of Labour has caused a huge cases of employees turnover. Due that turnover, the knowledge retention has been affected. This paper examines the employee turnover sources, its effects and forwards a suggested strategy that linked to HRM on how to minimize the lost knowledge that caused by the localization program Nitaqat.
\end{abstract}

Index Terms-Employee turnover, Localization, Nitaqat, Saudia Arabia, Human Resource Management, Knowledge Management.

\section{INTRODUCTION}

Around two years ago, the Kingdom of Saudi Arabia introduced a new program, called Nitaqat for supporting the Saudization initiative that has been discussed since the beginning of the millennium. Saudization means replacing foreign employees in the Kingdom of Saudi Arabia with locals [1]. The aim of this initiative is to ensure that a certain proportion of jobs in Saudi Arabia are occupied by locals in order to place limitation on foreign workers. One of the biggest problems in Saudi Arabia is the unemployment rate of local residents. In 2004, according to Looney, the percentage of non-working Saudis was $8.2 \%$ [2]. This increased in 2010 to $10.8 \%$. Moreover, these figures are for male citizens only; other estimates for both male and female citizens range as high as 30\% [3].

"Nitaqat" is an Arabic word that means "ranges" or "limits".

The primary goal of this program is to assist the Saudization initiative and to absorb Saudi job seekers. Theoretically, this should reduce the unemployment rate in the country by forcing companies and firms to hire Saudis. The Saudi Ministry of Labour announced the program on June 2011. The program sets penalties for non-compliance with the rules. One of the decisions that accompanied this program was the restriction of foreign workers who had lived in Saudi Arabia for less than 6 years for both red zone companies (companies having less than $10 \%$ local workers) and yellow zone companies (from 10-20\% local workers). Companies in Saudi Arabia that were not employing enough local workers under the new rules were notified they may

Manuscript received May 6, 2014; revised July 10, 2014.

The authors are with the School of Property, Construction and Project Management, RMIT University, Melbourne, Australia (email: nalshanbri@hotmail.com, m.ali.noor@hotmail.com, kevin.zhang@rmit.edu.au, tayyab.maqsood@rmit.edu.au ). have their foreign workers taken away through the non-renewal of visas resulting into the inability to obtain renewed working visas for existing workers. The Saudi Labour Minister mentioned that it was the right time to begin to force companies in the Saudi private sector to hire locals [4].

Nitaqat divided the Saudi private sector enterprises to four zones, currently some of them are situated in the green and excellent ranges which have achieved reasonable and acceptable rates of localization. The enterprises that are located in the yellow and red zones, they did not employ Saudis, or that the Saudization rate is less than acceptable and they are given sufficient time to correct their positions in order to move to the green and the excellent zones by the Saudi ministry of Labour.

The aim of the ministry through Nitiqat program is to use Saudization rates as a competitive feature among the private sector firms.

The firms that engaged with Nitiqat and within the excellent and the green zones will be provided with a package of facilities and motivations, making it easier for dealings with their employees and worker unions and gives them sufficient flexibility to achieve the levels of growth. The program also aims to create a much better balance between the advantages of hiring a foreign worker and the Saudi worker by raising the cost of maintaining foreign workers in the red and yellow ranges. Also, Nitiqat can be considered as a monitoring tool for the Saudi labour market that aims to achieve a growth in jobs for local residents in the private sector and to move the unemployment rate in the country to lower levels.

Nitaqat, as the Saudi ministry claims, came into place to meet the directives of the country with regards to finding opportunities for Saudi Arabia's citizens, and to achieve growth and stability in both social and economic areas as it meets the needs of two important stakeholders; businessmen with their needs in expanding their businesses and improving the development of the national economy.

The second stakeholders are the Saudis, in terms of these creations of jobs are for them aiming to absorb and integrate them into the work force in order to improve the development of the national economy.

Nitaqat program provides an integrated set of incentives for those companies that are working to increase their Saudi employees, which also clearly defines the consequences faced by those companies that are unable to achieve the needed percentage of Saudi employees or have less than required. As it was mentioned before, Nitaqat classify the private sector enterprises to (4) ranges (platinum, green, yellow and red) as well as enterprises that have less than 9 employees. The Saudi ministry of Labour take in 
consideration both of the unemployment and the localization from a holistic perspective and believes in combining long-term solutions through policies that generate opportunities and align output in addition to replacement policies through initiatives and programs that provide short term solutions.

Therefore the ministry focuses on the quality factor in their systems in order to achieve the country's current development plan, which states the need to expedite the growth and development of Saudi human resources in both quality and quantity so that the Saudi's economy at the end will occupy its proper position on the global competitiveness map.

Reference [5] argued that employees could be considered valuable assets that help influence the competitiveness of organizations. However, in the case of Saudi's new localization program, the knowledge that foreign workers hold is their most valuable asset. When employees leave any organization, knowledge leaves with them as well [6].

Accordingly, and in order to transfer knowledge successfully to locals, the organisation should act soon to retain the knowledge held by these workers in order to maintain the competitive advantage of intellectual capital.

According to reference [7], lost knowledge can have an impact on any organization by reducing innovative capacity, reducing organizational efficiency, giving competitors an advantage, and increasing vulnerability. These effects can results from knowledge loss on an organizational scale.

More importantly, losing knowledge due employee turnover across organizations has great effects on a country that go beyond the simple impact on one organization. If Saudi Arabia keeps forcing companies to replace their non-local employees without considering the importance of knowledge transfer and the effects of the employee turnover, the same effects felt on the organizational level would be felt in a tremendous way on a much larger scale.

\section{DEFINITION OF EMPlOYEE TURNOVER, ITS SOURCES AND THE ROLE OF HUMAN RESOURCE MANAGEMENT (HRM) IN MinimizInG KNOWLEDGE LOSS THAT CAUSED BY EMPLOYEES TURNOVER}

Reference [8] defined Employees' turnover as "the rotation of workers around the labour market; between firms, jobs and occupations; and between the states of employment and unemployment". The employee turnover is always expensive, detrimental and always affects the organizational performance [9]. Replacing leaving employees and selecting, recruiting and training the new ones will cost a lot of time, money and effort [10]. Reference [11] find that the relationship between total turnover and organizational performance is significant in a negative way. The sources of employee turnover has been discussed and listed in many studies before [8], [12]-[14]; these include job stress, lack of commitment in the organization, extensive job pressures, job dissatisfaction, low wages, powerlessness, economic reasons, organizational instability, poor personnel ,toxic workplace environment and poor Human Resource Management policies and procedures, and lack of motivation in the company. Reference [14] shows that employee's turnover has many effects on the company performance and can be considered expensive due to hidden costs associated with paying the leaving employees and hiring the new ones. In the case of the Saudi Arabia's localization program "Nitaqat", the program caused a huge employee turnover in both red zone and yellow zone companies. The loss of the leaving employee's knowledge is one of the most important issues that these companies in red and yellow zones should take care of.

Reference [15] states that one of the main reasons knowledge does not flow within organizations is that people "stick" to their knowledge. HRM has a major role in facilitating knowledge transfer between the leaving employees and the new ones through the management of people. Reference [16] mentioned that facilitating knowledge flow amongst employees in order to avoid knowledge loss could be considered as a key issue for succession planning. One could argue that HR departments and managers would not be responsible for the establishment of $\mathrm{KM}$ in organizations; their role is to facilitate the movement of knowledge and assist in the transformational process of knowledge transfer by performing their regular activities. However, HR managers should review their job responsibilities and look at big picture of knowledge retention in order to act as a strategic partner for organizations.

Research begun in the 1990s strongly asserts that organizations that could effectively attract and retain the market's best and brightest talent would be able to turn this to economic and strategic advantage [17]-[19]. On the other hand, different research suggests that the previously mentioned advantages will rest with organizations that can retain knowledge and facilitate knowledge transfer between employees [20], [21]. The current localization program in Saudi Arabia has led to the need to consider new plans to retain knowledge that will be caused from employees' turnover in order to retain economic and strategic advantage.

The general role and responsibilities of an HR department should be flexible enough to assist in knowledge transfer and, accordingly, in maintaining the competitive advantage of an organization. According to reference [22], the traditional HRM domains revolve around selection, training, appraisal, rewards, and performance management systems. These HRM domains take a "different colour" when they contribute to organizational knowledge assets [23]. According to Reference [24], HR professionals confront five key challenges in dealing with knowledge: developing and sustaining the knowledge culture within an organization; accessing employees' tacit knowledge; securing trust and commitment between employees; handling non-traditional employees such as knowledge workers; and "handling the organizational vulnerabilities arising out of a heavy dependence on key knowledge workers" [25].

Reference [26] suggested that HR departments have to play "the leading role" in facilitating knowledge management and transfer to enable the organization to maximize the benefit of the retained knowledge.

Reference [27] argued that HR management functions need a transformation in dealing with employees in order to achieve a sustainability of intellectual capital (IC). He also 
considered IC as a competitive advantage in the knowledge economy.

As mentioned before, most of the factors that cause knowledge loss are directly related to the employee turnover. Accordingly, retaining needed knowledge from departing employees requires a holistic approach. HR departments must create the needed infrastructure for knowledge retention. Reference [28] indicates that Organization with strong HR policies and strong communication systems enjoyed lower turnover of staff which can be linked to loss of knowledge.

All the discussion thus far highlights issues related to employees more than knowledge systems, and suggests that HRM strategies need to be equipped with knowledge processes in order to achieve effective knowledge management and to minimize the effects of employees' turnover. The next few sections evaluate HRM main domains and their effects on knowledge management.

\section{A. Recruitment and Selecting}

Recruitment can be considered as "a knowledge acquisition technique" that involves the determination of requirements related to organizational knowledge and the selection and hiring of individuals deemed to possess such knowledge.

Consideration of the requirements of organizational knowledge in the recruitment and selection of hires was recommended as an organizational best practice by [7]. Many organizations adopt highly advanced and complex methods of selecting and recruiting employees to attract the best talent in the market. However, this is not the best way for facilitating knowledge management. Many studies have shown that selecting the best talent in the market cannot guarantee knowledge sharing. Rather, gaining commitment from both the source and recipient of knowledge in a knowledge sharing arrangement should be the focus [7], [23], [29]. Furthermore, the social skill of having the propensity to share and develop is another important issue behind effective knowledge transfer and management.

The selection of individuals with competent skills and the right attitude is essential for creating knowledgeable teams (or a knowledge repository). Highly innovative selection processes have been introduced that are technologically sound and efficient [30]. Selection processes are highly customized to the job descriptions and corresponding skills and competencies that ensure the right candidates are hired for the job. However, such customized selection processes can conceal certain employee behaviors [23]. Another implication for appropriate selection is the person-organization (PO) fit, which intends to ensure that the perceived values of the new staff are similar to the organizational values or, at least, can be adjusted according to the organizational culture. Such non-job-related criteria are usually assessed through face-to-face interviews, which do not possess absolute predictive validity [31]. Moreover, such selective hiring procedures can slow down or even obstruct knowledge sharing between individuals from different departments [32]. However, certain job descriptions have to adhere to specific skills. In such cases, codified knowledge can be of great assistance in knowledge transfer to individuals from other functions.
Ultimately, the main idea behind a selection process that keeps knowledge management in mind is that the value perception of the hired individuals should fit with the organization's values. This requires highly selective hiring, which will also aid in higher level of knowledge management, as hypothesized by [33]. With this in mind, HR managers must keep many questions top of mind when selecting new team members for an organization. What about the commitment of the new team member to share their knowledge when they leave the organization? What is the ability of the new team member to absorb knowledge? The management and other important personnel involved with the hiring of the new team member must also be sensitive to these issues. The intellectual and the personal compatibility between the new joiner and the leaving employee, play a significant role in facilitating the transfer of knowledge and to reduce the cost of the employee turnover. The organizations in both red and yellow zones in the Saudi private sector have to look carefully to the selection process and to give the chance to the leaving employee to participate in the selection process of new employees.

\section{B. Training and Development}

Training is a process that directly connects HR personnel with other employees in order to source knowledge transfer, which stands at the core of any knowledge management process. Training plays an important role in the development of the three dimensions of organizational knowledge: breadth/depth of knowledge, competence, and exploratory/exploitative knowledge [23]. Training provides an opportunity to improve employee performance through work-related knowledge and skill-development [34]. Knowledge related to skill-specific work can be transferred through systematic and frequent training. Reference [33] hypothesized that training leads to higher knowledge transfer.

Frequent training that supplements organizational knowledge can be accomplished by creating a learning culture and improves competitiveness, enhances technical and social learning, results in knowledge acquisition outside one's main domain, and improves overall business performance. Training on documentation is a great way to transfer knowledge. HR departments in the private sector in the organizations that are committed to Nitaqat need to be ready and prepared to invest time and effort in developing new members of their organizations. Using training as one forum to facilitate knowledge transfer will foster the adoption of Nitaqat and help create sustainable advantage for Saudi Arabian organizations.

\section{Performance Management}

Performance management processes can make an important contribution to knowledge management and employee turnover by setting behavioral expectations related to knowledge-sharing, ensuring that actual behaviors are reviewed and in establishing appropriate financial or non-financial rewards [35]. Performance appraisals are the key employee performance assessment process and aim to provide role and goal clarity to individuals. Reference [36] posited that employee performance evaluations can help 
drive knowledge management by providing feedback for leadership, enhancing the decision making capabilities of individuals, creating interpersonal relationships, minimizing high turnover and absenteeism, and clarifying roles and goals Performance appraisals should be designed to evaluate the degree to which certain competencies are used; this can help drive the proper direction for further training and development [23].

Performance appraisals can also be used to evaluate knowledge sharing practices of employees. Moreover, a good performance appraisal system can help align individual actions and knowledge to organizational strategies. Strategies of employee selection and training assist in acquisition and development of individual knowledge and experiences for the organization, which can be moulded to match the organizational strategies through performance management systems. Performance management also helps in the effective review of the selection of (and requirements for) training strategies [37]. Therefore, an effective performance appraisal system enhances the knowledge creation and sharing process, which can result in a higher level of knowledge management and lower costs of employee turnover.

\section{Rewards and Employees Turnover}

Employees must be motivated to improve knowledge sharing, and rewards and recognition must improve employee motivation and commitment which can affect directly on the employee turnover. Numerous researchers have emphasized that reward structures are necessary to recognize optimal learning and knowledge sharing behaviors in order to motivate people to communicate and share knowledge [24], [33], [38].

Motivation by rewards and recognitions will assist in encouraging innovation in different aspects such as products, services, or communication style between staff and also will minimize the employee turnover. HR activities and procedures that are backed by a reward system is an excellent tool to minimize the employees turnover and to positively affect the organizational culture through group performance, knowledge sharing, and innovative thinking [39].

HR departments have to assess the ability of each departing staff member to transfer their knowledge to remaining workers, and moreover must assess their level of motivation to do so, as motivation is critical in any strong knowledge management culture [40].

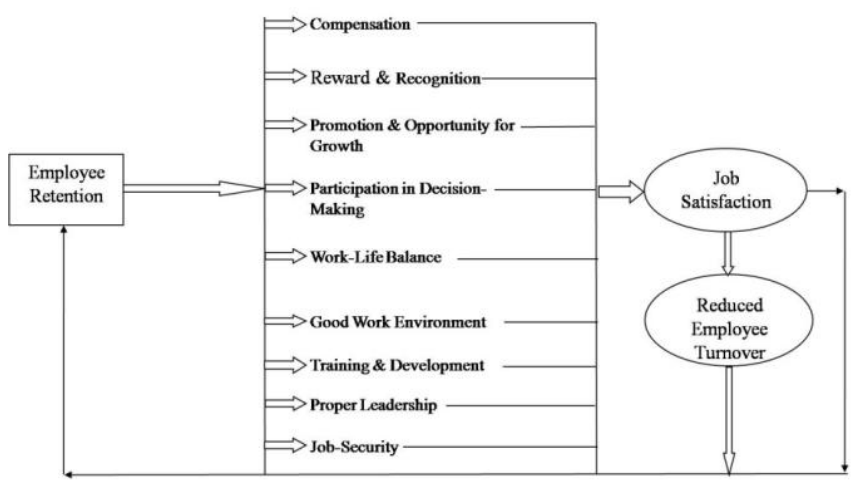

Fig. 1. The employee retention and job satisfaction model.
The above model (see Fig. 1) was suggested by [41], showing nine factors and concludes and explains the relationship between these factors, and both job satisfaction and employee turnover. Same factors also have a strong relationship with knowledge retention in case of the higher employee turnover like the recent case in Saudi Arabia which will be discussed in the next section of this paper.

\section{NITAQAT’S STATUS IN THE KINGDOM}

The Nitaqat localization program that focuses more on the number of Saudi employees in each company rather than their

capabilities, it has forced many companies to hire Saudis just to stay away from both red and yellow zones and enter into the green zone in order to get the maximum benefits from the Saudi Ministry of Labor. Some of the benefits that the green zone companies will be able to get are:

1) Receiving visa applications in accordance with the rules of the new employment standards in one condition; if the company maintained its position in the green zone after grants and not to apply for new visas more than once every two months.

2) Green zone enterprises have the right to obtain only one alternative visa for each two final exit visas.

3 ) the ability of changing the expat's careers to other occupations, including the careers that are limited to the Saudis; except the excluded careers that were mentioned in the decision of the Council of Ministers (recruitment officers, reception, commentators and government departments, auditors and treasurers, and security guards).

4) For the enterprises in the green zone, the Ministry is going to continue its services for only 6 months to those enterprises with an expired licenses or certificates of the other government agencies, such as Zakat certificate, professional licenses, commercial register license or municipal license.

5) The ability to renew the work permit visa for foreign workers, regardless of the duration of residence, in one condition; that the remaining duration in that visa is no more than three months on the renewal date.

6) The ability to contract with expats from enterprises that are located in the red zone and transfer their services without their current employer approval (with a condition, the company have to stay in the green range)

7) The ability to contract with expats from enterprises that are located in the red or yellow zones and transfer their services without their current employer approval.

The last benefit of Nitaqat was considered as a disadvantage in reference [42]. He mentioned that the new Nitaqat program allows non local employees who are working with the red or yellow zone companies to transfer their services to companies and enterprises in the green zone without their current employer approval. That issue caused a huge number of employees turnover in both red and yellow zones companies who failed to hire more Saudis.

Reference [42] also mentioned that although Nitaqat helped around 250,000 Saudis in finding jobs since it has been introduced in the country, the program failed to help the 
majority of these Saudis to stay in their current job and not move from one company to another if they found a better position.

Reference [42] also said that $70 \%$ of the companies in the private sector have been suffered in the first year from "employee turnover". Moreover, the Saudi ministry of labor in their yearly statistical book listed that there are around 400 companies in the Saudi private sector which have ended their businesses due to their inability of meeting the minimum requirements of hiring locals.

A few companies started just to use a way that is well known as "Delusive Saudization" or "Fake Saudization" by which they include just the names of Saudi national as employees in the company's system in order to avoid penalties that related to Nitaqat. At the beginning of this year the Ministry of Labor has unveiled a "comprehensive plan" to control and end the fake employment.

One of the cases that been raised to the surface recently in the Kingdom is, what the General Organization for Social Insurance (GOSI) published in their statistical yearly book of 2013, which indicates the presence of 104,000 Saudi women registered in their system as working in the construction sector. This incident made many in the country to wonder about the authenticity of that number and the Ministry of Labor were asked to check on it.

The Saudi ministry of labour established follow-up teams from of the ministry employees and they were sent to all cities of the Kingdom of Saudi Arabia. The mission of those teams as the ministry published in their website is to inspect the Saudi's private sector facilities and the enterprises and see how these enterprises are following Nitaqat and their statues for the Saudization rates through rounds of field inspections. The ministry has recently added 1000 new inspectors in the Kingdom to assist in Nitaqat program.

The ministry said that they are setting penalties that could reach five years' imprisonment and fines of up to SR10 million (U.S.\$2.6 million), in addition to preventing violators from recruiting expatriates, seeking loans and transferring sponsorship from business owners.

Companies in Saudi Arabia have to improve their recruitment plans in order to achieve not only the needed proportion of the Saudization rate but also to raise the focus on the capabilities of the new employees.

The Saudi ministry of labour also has to continue the development of Nitaqat program to make it a more accurate and to focus towards the previous desired goals, taking advantage of the experiences of the developed countries, and what makes the Saudi's labour policies optimally reach in raising productivity and provide job opportunities for citizens in the most promising areas.

\section{CONCLUSION}

Recognizing the threat of losing knowledge as caused by the employees turnover to organizations and to a country's economy is a critical first step in addressing this phenomenon. Retaining the employees or the needed knowledge in organizations relies on people and the ability of HR departments to modify human behavior; in turn, the success of this endeavor depends on the commitment of all HR managers as they collaborate with the departing employees as well as with the staff that is replacing them.

As was discussed earlier in this paper, the HR Department should act as a strategic partner for organizations and consider the above strategies and take them into account to facilitate knowledge between employees and to minimize the employee's turnover. Currently, however, this role is undermined by the fact that HR departments are often relegated to a supportive, strictly administrative role. This paper looked at one particular part of the problem with the current situation in Saudi Arabia, and highlighted the role of HRM in facilitating knowledge that related to the employees turnover. The effectiveness of HRM in facilitating the movement of knowledge, and the role of both knowledge management, the HRM in supporting employee replacement processes and the employees turnover, are parts of a $\mathrm{PhD}$ study that aims to investigate the Saudi Arabia's new localization program "Nitaqat".

The research will further examine these strategies in order to understand the impact of both knowledge management and HRM strategies on organizational effectiveness to avoid losing knowledge while maintaining the competitive advantage of Intellectual Capital. Furthermore, the study will suggest a mechanism to transfer needed knowledge to new employees.

\section{REFERENCES}

[1] A. S. A. Dosary and S. M. Rahman, "Saudization (localization) - a critical review," Human Resource Development International, vol. 8, pp. 495 - 502, 2005.

[2] R. Looney, "Can saudi arabia reform its economy in time to head off disaster?” Strategic Insights, vol. 3, 2004.

[3] M. A. Ramady, The Saudi Arabian Economy: Policies, Achievements, and Challenges, 2nd ed., Springer, 2010.

[4] A. News, "Boosting saudization, nitaqat program offers expats greater mobility," in Arab News, Riyadh, 2011.

[5] H. Yeganeh and Z. Su, "An examination of human resource management practices in Iranian public sector," Personnel Review, vol. 37, pp. 203-221, 2008.

[6] M. P. Phaladi, "Knowledge transfer and retention: the case of a public water utility in South Africa," Master of Philosophy in Information and Knowledge Management, Department of Information Science, University of Stellenbosch, Stellenbosch, 2011.

[7] D. DeLong, "Knowledge Loss Prevention: Five keys to decisions vis-à-vis an ageing workforce," Inside Knowledge, vol. 11, pp. 15-19, 2008.

[8] S. M. Abbasi and K. W. Hollman, "Turnover: the real bottom line," Public Personnel Management, vol. 29, pp. 333-342, September 1, 2000.

[9] C. W. Mueller and J. L. Price, "Some consequences of turnover: a work wnit analysis," Human Relations, vol. 42, pp. 389-402, May 1, 1989.

[10] K. W. Mossholder, R. P. Settoon, and S. C. Henagan, "A relational perspective on turnover: examining structural, attitudinal, and behavioral predictors," Academy of Management Journal, vol. 48, pp. 607-618, August 1, 2005.

[11] T.-Y. Park and J. D. Shaw, "Turnover rates and organizational performance: A meta-analysis,” Journal of Applied Psychology, vol. 98, pp. 268-309, 2013.

[12] L. Firth, D. J. Mellor, K. A. Moore, and C. Loquet, "How can managers reduce employee intention to quit?" Journal of Managerial Psychology, vol. 19 , pp. 170-187, 2004

[13] R. M. Negrin and S. S. Tzafrir, "Job search modes and turnover," Career Development International, vol. 9, pp. 442-458, 2004.

[14] H. Ongori, "A review of the literature on employee turnover," African Journal of Business Management, vol. 1, pp. 49-54, 2007.

[15] G. Szulanski, Sticky Knowledge: Barriers to Knowing in the Firm, SAGE Publications, 2003.

[16] K. Butler and D. E. R. Tarry, "Succession planning: putting an organization's knowledge to work," Nature Biotechnology, vol. 20, pp. 201-202, 2002. 
[17] A. F. Smith and T. Kelly, Human Capital in the Digital Economy, the Organization of the Future, San Francisco, CA: Jossey-Bass Publishers, pp. 199-212, 1997.

[18] J.-M. Hiltrop, "The quest for the best: human resource practices to attract and retain talent," European Management Journal, vol. 17, pp. 422-430, 1999.

[19] R. E. Lewis and R. J. Heckman, "Talent management: a critical review," Human Resource Management Review, vol. 16, pp. 139-154, 2006.

[20] C. Carter and H. Scarbrough, "Towards a second generation of KM? The people management challenge," Education and Training, vol. 43, pp. $215-224,2001$.

[21] S. Bano, M. A. Khan, Q. H. U. Rehman, and A. A. Humayoun, "Schematizing talent management, a core business issue," Far East Journal of Psychology and Business, vol. 2, pp. 4-16, 2010.

[22] J. Storey, "Introduction from personnel management to human resource management," in New Perspectives on Human Resource Management, J. Storey, Ed., ed London: Routledge, 1989, pp. 1-18.

[23] S. Narasimha, "Organizational knowledge, human resource management, and sustained competitive advantage: towards a framework," Competitiveness Review: An International Business Journal incorporating Journal of Global Competitiveness, vol. 10, pp. $123-135,2000$

[24] J. Storey and P. Quintas, "Knowledge management and HRM," in Human Resource Management: A Critical Text, J. Storey, Ed., London: Thomson Learning, 2001.

[25] F. Afiouni, "Human resource management and knowledge management: a road map towards improving organizational performance," The Journal of American Academy of Business, Cambridge, vol. 11, pp. 124-130, 2007.

[26] S. Gourlay, "Knowledge management and HRD," Human Resource Development International, vol. 4, pp. 27-46, 2001.

[27] M. Thite, "Strategic positioning of HRM in knowledge-based organizations," The Learning Organization, vol. 11, pp. 28-44, 2004.

[28] B. Labov, "Inspiring employees the easy way," Incentive, vol. 171, pp. 114-18, 1997.

[29] L. Argote, P. Ingram, J. M. Levine, and R. L. Moreland, "Knowledge transfer in organizations: learning from the experience of others," Organizational Behavior and Human Decision Processes, vol. 82, pp. $1-8,2000$.

[30] H. Scarbrough, "Knowledge management, HRM and the innovation process," International Journal of Manpower, vol. 24, pp. 501-516, 2003.

[31] J. A. Chatman, "Matching people and organizations - selection and socialization in public accounting firms," Administrative Science Quarterly, vol. 36, pp. 459-484, Sep 1991.

[32] G. Currie and M. Kerrin, "Human resource management and knowledge management: enhancing knowledge sharing in a pharmaceutical company," International Journal of Human Resource Management, vol. 14, pp. 1027-1045, Aug. 2003.

[33] W. C. Har, T. B. In, L. S. Phaik, and L. V. Hsien, "The impact of HRM practices on Km: a conceptual model," Australian Journal of Basic and Applied Sciences, vol. 4, pp. 6281-6291, 2010.

[34] R. A. Swanson, "HRD theory, real or imagined?" Human Resource Development International, vol. 2, pp. 2-5, 1999.

[35] M. Armstrong, A Handbook of Human Resource Management Practice, 10th ed., London: Kogan Page, 2006.

[36] F. Soliman and K. Spooner, "Strategies for implementing knowledge management: role of human resources management," Journal of Knowledge Management, vol. 4, pp. 337-345, 2000.

[37] S. Bürkland, "Managing the development of valuable intellectual capital," The Role of Management Control, University of Vaasa, 2009.

[38] K. M. Bartol and A. Srivastava, "Encouraging knowledge sharing: the role of organizational reward systems," Journal of Leadership and Organizational Studies, vol. 9, pp. 64-64-76, 2002.

[39] S. Yahya and W.-K. Goh, "Managing human resources toward achieving knowledge management," Journal of Knowledge Management, vol. 6, pp. 457-468, 2002.

[40] A. H. Gold, A. Malhotra, and A. H. Segars, "Knowledge management: an organizational capabilities perspective," Journal of Management Information Systems, vol. 18, pp. 185-214, 2001.

[41] B. L. Das and M. Baruah, "Employee retention: a review of literature," Journal of Business and Management, vol. 14, pp. 8-16, 2013.

[42] H. Alenizi, "Employee turnover, the silent threat of the ministry of labour's initiatives," in Alriyadh, vol. 16640, ed., Riyadh, 2013.

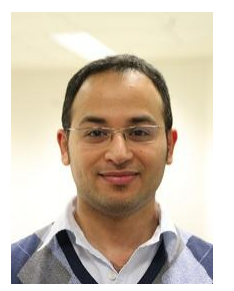

Nawaf M. Alshanbri was born in Saudi Arabia and received his bachelor degree in industrial engineering from King Abdul Aziz University in Jeddah, Saudi Arabia in 2004 and master in engineering management degree from RMIT University in Melbourne, Australia in 2011. Currently, he is a PhD student in RMIT. His $\mathrm{PhD}$ research deals with understanding the role of knowledge management and human resource management in assisting the employee's replacement process in Saudi Arabia. Nawaf has worked for 4 years as human resource specialist in a consulting company in Saudi Arabia (integrated visions, Jeddah, 2004 - 2008)

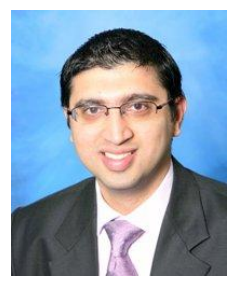

Malik M. A. Khalfan is an associate professor in School of Property, Construction and Project Management at RMIT University. Malik was born in Karachi and completed his civil engineering degree from NED University, Karachi, Pakistan and masters in construction project management and $\mathrm{PhD}$ in construction management, both from Loughborough University, UK. Since joining RMIT in 2009, Malik has collaborated with academic staff to conduct collaborative research, resulted in several research publications with a Prof Tayyab Maqsood and research projects with Prof. Kerry London. In addition to the above, Malik has collaborated with researchers from around the world towards joint publication and presently serving as the joint co-ordinator for CIB W102 knowledge management in building working commission along with Prof. Charles Egbu from Salford University, UK. Malik is also serving on the editorial board of many journals and served as scientific committee members for various conferences. Malik has also delivered various guest lectures as visiting fellow and presented his research work at number of conferences in last 15 years.

Debopriya Dutta received a bachelor degree in psychology from Christ College, Bangalore University and a master degree degree from Delhi University in applied psychology (specialization in organizational behavior). In addition, she has a post graduate diploma in counseling from Montfort College, Martin Luther Christian University, India. She was born in India and before migrating to Australia, she worked as an intern with Defence Institute of Psychological Research, Ministry of Defence, India

Kevin Zhang is an associate professor at School of Civil, Environmental and Chemical Engineering, at RMIT University. He was born in China and after competing his master of management (construction economics and management) from Chongqing University, P. R. China he moved to Australia and did his PhD in construction management from Queensland University of Technology, Australia.

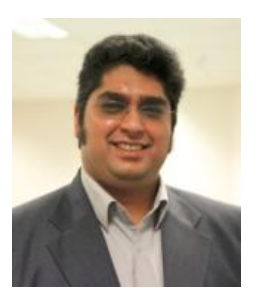

Tayyab Maqsood is currently working as an associate professor in project management and deputy head-learning and teaching in the school of property, construction and project management at RMIT University. He leads a team of highly capable academics associated with the delivery of undergraduate and postgraduate programs in construction, project management and property disciplines. He was born in Lahore and graduated as a civil engineer in 1995 from UET Lahore and obtained a master of engineering degree in construction engineering and management in 1999 from AIT Thailand where he was awarded a prestigious Mahesh Verma award. He has worked in Hong Kong, UK, Thailand, and Pakistan in various capacities as lecturer, project engineer and research associate before settling in Australia in 2002. He earned his $\mathrm{PhD}$ in the area of project management from RMIT University in 2006 specialising in knowledge management, organisational learning and innovation in construction industry. $\mathrm{He}$ is a recognised expert in this area and has widely published and presented internationally. He has authored/co-authored over 70 peer reviewed publications (conference papers, journal papers and book chapters). He is a member of institution of engineers Australia and Project Management Institute. 